\title{
Cost Affecting Factors Related to Fillet Joints
}

\author{
Erik Åstrand $^{1,3}$, Anna Ericson Öberg ${ }^{2,3}$, Bertil Jonsson ${ }^{1}$ \\ ${ }^{1}$ Volvo Construction Equipment, Braås, Sweden. ${ }^{2}$ Volvo Construction Equipment, Arvika, \\ Sweden. ${ }^{3}$ Department of Materials and Manufacturing Technology, Chalmers University of \\ Technology; Gothenburg, Sweden.
}

\begin{abstract}
Fillet welds are by far the most frequent arc welding joint type in the fabrication industry with about $80 \%$ of all arc welded joints worldwide. Although the joint is well established, there are many aspects to consider when producing an ideal weld. This paper reveals and connects several problematic issues related to the joint type and the difficulties to fabricate a weld with correct strength, cost, and quality.
\end{abstract}

Excessive welding of fillet welds is common, resulting in increased fabrication cost. There could be several causes for this; the designers do not customize the weld demand for the different stress levels and the production adds even more to handle the variation in the process. Previous studies shows that the combination of these factors can result in $100 \%$ extra weld metal, compared to what should be needed to fulfil the strength demands.

Inspections are another contributor to excess welding. The capability of the weld size measurement method used by welders and inspectors is unsatisfactory. Measurement system analyses show that the scatter from the measurement system itself is in the same range as the scatter from the process.

A critical summary of the current state-of-the-art is that fillet welds are hard to specify and fabricate with the right size, that the measuring method is incapable and the connection between size and strength is weak.

\section{Introduction}

Fillet weld joints are the most common joint type in the fabrication industry with around $80 \%$ of all joints made by arc welding (Cozens, 2003). The joint type does not need any weld preparation and has a large advantage compared to the groove joint. Large fillet welds however demand a large amount of deposition material and are seldom economical compared to a groove joint (Miller, 2011). 
Although the weld is common, there are still many aspects to consider to be able to produce an optimum fillet weld with respect to strength, cost, and quality for the application in question. Fillet welds require skilled welders and high heat input to get sufficient fusion/penetration. Internal weld defects cannot be detected by visual inspection and are problematic to identify with other NDT (non destructive testing) methods. As a consequence, most of the inspection efforts are instead focusing on measuring the weld size (Cozens, 2003). The main concern, within the industry, becomes to produce a weld of correct size. Excessively large welds are often the result, which leads to increased welding costs and further distortions of the structure.

Overwelding of fillet weld is common in industry and could be related to three potential sources. The first source is the design department, that creates the specification of the fillet weld size requirement which the welder should meet. The second source is the welder, who could produce a weld which is larger or has a different shape than specified. The third potential source of overwelding is "bad fitup" between the parts. (Miller, 2011)

The welders usually add extra safety margins to be on the safe side. Causes for this could be a desire to avoid remarks from inspection and a belief that larger welds are stronger. Safety factors from designers and welders may lead to twice the volume of a correctly sized fillet weld (Cozens, 2003).

\section{Factors Creating Excessive Fabrication Cost}

The authors have identified four main causes which all together contribute to the cost and to the quality of a welded structure. The identified causes are valid for most structures with predominantly fillet welds, but the main focus is on fatigue loaded structures.

\subsection{Oversized Weld Demands from Design}

The designer has the main influence on the structural cost, depending on the chosen design of the structure. When the main design is set, the fabrication costs are determined by the weld demands. A master thesis work, was performed where the design demands on a structural part of a hauler were evaluated. The chosen part, called bogie beam, has a box design and about $18 \mathrm{~m}$ of fillet weld joints around the web plates to give the structure sufficient strength. These welds have all the same demand regarding weld size, weld class, criticality and penetration. As a part of the study, the structure was evaluated to identify possibilities to re- 
duce the weld demands, especially the weld size locally, without reducing the fatigue properties of the structure (Stemp, 2012).

The results showed that less than $2 \mathrm{~m}$ fillet welds are critical to the structure. The other welds also had unnecessary high demands, both regarding weld class and weld size. As an example it showed to be possible to reduce the throat size from 5 to $3 \mathrm{~mm}$ against the upper flange without affecting the structural integrity. In total, it is possible to reduce weld class demands for most welds and the specified weld metal weight with $28 \%$ without violating the fatigue life requirements (Stemp, 2012).

Unnecessary high demands gives a higher weld cost obviously, the arc on time for a weld are proportional to the weld metal weight which means that the arc on time can be reduced with $28 \%$. Demands on weld bead appearance could also result in extra safety margins in the robot process and/or a vast amount of weld repairs which do not affect the structural integrity.

\subsection{Excessive Weld Sizes in Fabrication}

It was previously stated that welders often add extra safety margins "to be on the safe side", in order to avoid remarks and also from the belief that a larger weld would make it stronger (Cozens, 2003).

Ericson Öberg et al. (2012) has performed an investigation to determine the extent of overwelding, its causes and the effect on fabrication cost. It has been found that the welding robots were programmed to handle possible gaps without getting an undersized weld. Together with organizational issues and difficulties to measure the weld size an over welding of around $40 \%$ was observed.

Experiments were performed to measure the relation between throat size and gap. Gaps of $1 \mathrm{~mm}$ gives almost no reduction of throat size while $2 \mathrm{~mm}$ gaps give a reduced throat size of $\sim 0.5 \mathrm{~mm}$. Larger gaps result in wider scatter and require a root pass to give sufficient throat size. (Ericson Öberg, et al., 2012)

The result of the over welding can be divided into two areas; the area that gives a fillet shape itself (41\%) and the area which includes deviations from the theoretical shape (59\%) (Ericson Öberg, et al., 2012). 


\subsection{Inspection with Large Variation}

Determining the weld size could be seen as a simple operation and there are several types of weld gauges used to assure the correct weld size. The gauges have clear limitations in the measurement according to performed Measure Systems Analyses, MSA. The accuracy is uncertain and the capability is low, especially when no standardized measure procedures are used. The variation from repeatability and reproducibility can be larger than the variation from the process (Ericson Öberg, et al., 2012).

The results confirm an earlier study where the same conclusions were made. In that study the throat size was measured on three randomly chosen structures at two factories. $60 \%$ of the total variation could in this case be related to the measure system and the noise in the measurement was around $0.3 \mathrm{~mm}$. The operator sees the total variation of both welding and measuring. As a consequence, the target value for the throat size is adjusted upwards to avoid rework due to small weld sizes. In the study the average weld size was $5.8 \mathrm{~mm}$ to compare with the drawing demand of throat size $5 \mathrm{~mm}$ (Hammersberg \& Olsson, 2010).

\subsection{Relevance of Throat Size Demands for Fatigue}

The throat size is seen as the basic demand for fillet welds, which is true when it comes to static load of fillet welds without penetration. For fatigue loaded structures, where the local weld geometry is more prominent, the throat size is not an appropriate measure on the weld's structural integrity.

For many applications with load carrying welds, the root side is the critical part of the fillet weld, especially for welds with an open root. In these cases the throat thickness is inferior to the weld penetration (Olsson, et al., 1997). As a consequence, the relation between weld size and fatigue strength is weak and, in fact, welds with smaller throat size can offer higher penetration and higher strength for many applications (Åstrand, 2012).

For non-load carrying welds the weld size has an even lower effect. Several studies, both experimental and analytical, show this fact. The local weld toe geometry and its radius are instead of the highest importance (Asgher, 2012) (Lee, et al., 2009). 


\section{Discussion}

The use of fillet welds is well established within the fabrication industry and the process could be regarded as mature. This paper reveals several factors that put the joint type in another context; mainly because of the large variation in the welding process but also for other reasons.

The effect of global demands, when the design is using the same weld size on all fillet welds of a structure, gives a specified weld metal weight that could be reduced with $28 \%$ without affecting the fatigue life. This relates mainly to unnecessary large welds in regions of low stress (Stemp, 2012). Large structures have welds that are several meters long, with varying stress levels along the weld. However, the demands are often set for the critical point which leads to that the specified weld size demands are unnecessary high for most cross sections. Changed weld demands could also provide a more beneficial penetration which makes it possible to reduce the specified cross section area with equal or improved strength (Åstrand, 2012).

Overwelding in fabrication is partly used to cover for the variation during welding and from the variation in the inspection. The target value for the weld size on the shop floor is typically $1 \mathrm{~mm}$ larger than specified in order to avoid remarks and repairs due to small weld size.

A realistic estimation according to this paper is that the specified weld metal weight on the drawing is $30 \%$ too high due to global weld demands. The real weld weight is then $40 \%$ higher than specified because of variation in fabrication and inspection. This reveals theoretical potential to reduce the weld metal weight on heavy fatigue loaded structures with around $50 \%$ which is in accordance with the statement from (Cozens, 2003) in the introduction.

The impact on fabrication cost is massive and if half of the potential is used the weld cost can be reduced with at least $20 \%$ and the capacity in the welding equipment is increased with $25 \%$ calculated with an initial arc-time factor of $80 \%$.

The key to transform this potential into real money is to work with a cross functional process control and to reduce the variation in several steps. In cases were the weld demand are over specified could the process be trusted and e.g. the inspection be reduced in order not to introduce the variation from the inspection.

To improve the structural integrity it is also necessary to consider the purpose of the weld and to adopt the welding process for the critical spot of the weld. This can however require new weld procedures and weld demands, which as an example could be to specify weld demands on just one weld toe on a non-symmetrical weld. The throat size demands are most valid for static dimensioning of welds with no penetration, otherwise different weld demands are more relevant. 


\section{Conclusions}

The current state regarding fillet welds can be concluded in the following points:

- Fillet welds are often over specified and hard to produce according to the specified size

- The most common way to evaluate fillet welds have serious flaws

- The connection between the weld size and the strength of the weld is weak

- The variation leading to safety margins in each process step has a vast financial impact

\section{Acknowledgments}

The research work is partly funded by Vinnova (WIQ project) and the participating companies and universities. A great contribution has been made by the staff at Volvo CE Arvika and Braås.

\section{Bibliography}

Asgher, W., 2012. Effect of material grade on fatigue strength and residual stresses in high strength steel welds - Master thesis work, Stockholm: Royal Institute of Technology.

Cozens, M., 2003. Job knowledge 66: Fillet welded joins - a review of the practicalities, Cambridge: TWI.

Ericson Öberg, A. et al., 2012. The Influence of Correct Transfer of Weld Information on Production Cost. Linköping, s.n.

Hammersberg, P. \& Olsson, H., 2010. Statistical evaluation of welding quality in production. Borlänge, KTH.

Lee, C.-H., Chang, K.-H., Jang, G.-C. \& Lee, C.-Y., 2009. Effect of weld geometry on the fatigue life of non-load-carrying fillet. Engineering Failure Analysis, Issue 16, p. 849-855.

Miller, D., 2011. Control Cost by Avoiding Overwelding. Modern Steel Construction, Issue July.

Miller, D. K., 1998. Consider Penetration When Determining Fillet Weld Size. Welding Innivation, $\mathrm{XV}(1)$.

Olsson, K. E., Holm, D. \& Jakopovic, F., 1997. High strength welded box beams subjected to torsion and bending fatigue loads - Mode I and III stress intensity factors and crack growth predictions. Stockholm, EMAS.

Stemp, J., 2012. Fatigue assessment of a hauler bogie beam using FE analyses - Master thesis work, Munich: Technical University of Munich.

Weman, K., 2007. Svetshandbok. 3rd red. Stockholm: Liber.

Åstrand, E., 2012. Weld procedures and demands for improved fatigue strength of single load carrying fillet welds. Chicago, ASM International. 